\title{
Application of InSAR in Surface Deformation Monitoring of Electric Power Line Selection
}

\author{
Qiang Liu, Tianyong Chu, Yumin Tan*, Wuttichai Boonpook \\ School of Transportation Science and Engineering, Beihang University, Beijing, China \\ Email: 13131229@buaa.edu.cn, *zy1713107@buaa.edu.cn, wuttichai@buaa.edu.cn
}

How to cite this paper: Liu, Q., Chu, T.Y., Tan, Y.M. and Boonpook, W. (2019) Application of InSAR in Surface Deformation Monitoring of Electric Power Line Selection. Journal of Computer and Communications, 7, 39-52.

https://doi.org/10.4236/jcc.2019.77005

Received: April 26, 2019

Accepted: July 7, 2019

Published: July 10, 2019

\begin{abstract}
In the process of site selection and the facility construction in power engineering, the geological conditions of the foundation have an important impact on the displacement of completed power facilities. Usually, the conventional surface displacement has certain continuity in time and space. Therefore, in the initial stage of power line selection, the relatively stable geological conditions can greatly reduce the probability of major accidents due to ground deformation. As a new surface displacement monitoring method, InSAR can obtain the displacement monitoring results in long time series. This paper used 20 Sentinel-1A data to study the geological conditions of power line selection. Based on the fact that the vegetation coverage in the line selection area and the poor penetration of C-band data may cause serious body scattering correlation, we verified the possibility of obtaining accurate results in a long-time baseline with less influence on volume scattering decorrelation. Using this method, we obtained the surface history displacement line chart of the $220 \mathrm{kV}$ power line to be erected in Laiyuan to Quanyu, Hebei Province. By analyzing 10 high coherence points on the line, we found that the largest historical surface displacement in the 18 months is less than $30 \mathrm{~mm}$, and the maximum cumulative deformation rate is only $12 \mathrm{~mm} / \mathrm{a}$, which meets the requirements of power line erection.
\end{abstract}

\section{Keywords}

Power Line, Sentinel-1Adata, Volume Scattering Decorrelation, Long-Time Baseline

\section{Introduction}

The traditional power survey method is based on manual measurements. In recent years, with the development of satellite image technique, the use of satellite 
images for power line survey has gradually developed. Many researchers have studied the application of optical imaging in power line survey. In 2008, remote sensing image maps generated by Shuttle Radar Topography Mission (SRTM) and optical remote sensing images that met the power survey requirements were produced [1]. The method of using orthophotos and DEM to generate a three-dimensional map to see whether the line selection result is reasonable was also successfully applied [2]. With the rapid development of domestic satellites in China, optical remote sensing images based on domestic satellites are also used in power line selection, and the classification accuracy of the Gaofen 2 satellite images in the process of power line selection has been greatly improved [3]. In recent years, the research on power surveying using remote sensing images mapping has been more and more mature. But some new problems were gradually exposed. With the construction and operation of a large number of power transmission projects, the impact of equipment foundation settlement on the safe and economic operation of the power grid was getting more and more attention [4]. Power lines generally have a long span, the settlement of a single equipment foundation may thus cause the ultimate failure of the entire power system. Conventional mapping methods cannot get long-term observation of surface deformation and cannot have sufficient information to fully understand the geological conditions of the selected line area. The lack of surface deformation information may jeopardize the subsequent construction work. Interferometric Synthetic Aperture Radar (InSAR), which has been developed in recent decades, can work around the clock for the long-term sequence observations and the observation of surface deformation can reach an accuracy of millimeters. Currently, the InSAR technology is widely used in the mining detection and warning of natural disasters such as earthquake and landslides. In the area of power engineering, the Sentinel-1A data can be used to observe the settlement of the completed electrical equipment [5]. Long power lines generally need to be constructed cross areas with complex geological conditions and weak traffic conditions. However, some serious geological problems such as landslides and large settlement often show a certain continuity in time and space. Colesanti, et al. have used InSAR to get the surface deformation and predict the possibility of landslide occurrence [6]. Therefore, establishing the line in the areas with a small deformation in a long period will greatly increase the safety after the completion of the line. There are also some people who developed spatial analysis by using the some occurred disasters. Bathrellos, et al. completed a comprehensive evaluation of urban expansion by considering the natural disasters and surface features of the study area, which has a great significance to the development of the city [7]. Chen et al. used geographic information system (GIS) to analysis how the emergency shelters can adapt to the occurrence of the disaster [8]. In this paper, the advantages of high precision and long-term sequence of InSAR technology were used to study the surface deformation monitoring of power line selection. It can avoid damage to electrical facilities caused by improper site selection. 
D-InSAR is a method for observing surface deformation through satellites, which is well applied in areas with good coherence like cities [9] [10] [11]. In order to break through the influence of coherence factors, time series InSAR technology has gradually developed [12] [13]. Time series InSAR technology mainly includes Permanent Scatterers (PS-InSAR) and Small Baseline Subsets (SBAS-InSAR). They have been well applied in recent years [14] [15] [16]. The time-series InSAR technology can largely overcome the influence of SAR decoherence, greatly improve the accuracy of deformation monitoring, and make InSAR technology continuously applied to the monitoring of surface micro-deformation [17] [18]. In recent years, InSAR technology has been successfully applied in many fields such as landslide monitoring [19] [20], surface deformation monitoring in mining sites [21] [22] [23], seismic research [24] [25] [26] [27] [28], and road monitoring [29] [30] [31]. This paper used the 20-view Sentinel-1A images to carry out the research of InSAR technology in the geological survey of power line selection. The time span of the data is from October 10, 2015 to April 2, 2017. The long time series was used to ensure the accuracy of the geological survey.

\section{Study Area and Datasets}

\subsection{Study Area}

It was planned to set up a $220 \mathrm{kV}$ transmission line between Laiyuan and Quanyu, Hebei Province. In order to investigate the stability of geological conditions in this area, the study area selected in this paper is a rectangular area covering Laiyuan to Quanyu, with a range of $114.44^{\circ}-115.00^{\circ}$ east longitude and $38.73^{\circ}$ $39.41^{\circ}$ north latitude. The geomorphological features of the study area are mainly mountainous, with fewer water systems and large vegetation coverage. Figure 1 shows the studied area.

\subsection{Data Overview}

In our experiment, we analyzed C-band wide-range interference (IW) Sentinel-1A datasets downloaded from the official website of European Space Agency. The images were acquired in ascending orbit. According to our verification, we choose the data of vegetation fading period in winter (October to April). The selection process of power line requires sufficient information of surface deformation under long-term baselines to reflect the stability of the geological conditions. So, the experiment selected a total 20 scenes from October 10, 2015 to April 2, 2017 to ensure the performance of this method. The acquisition dates and special-temporal of Sentinel-1A data were selected as listed in Table 1 . The image of October 28, 2016 with zero baseline was the super master image chosen for SBAS-InSAR processing.

\section{Methodology}

D-InSAR was developed on the basis of InSAR technology. InSAR can acquire 


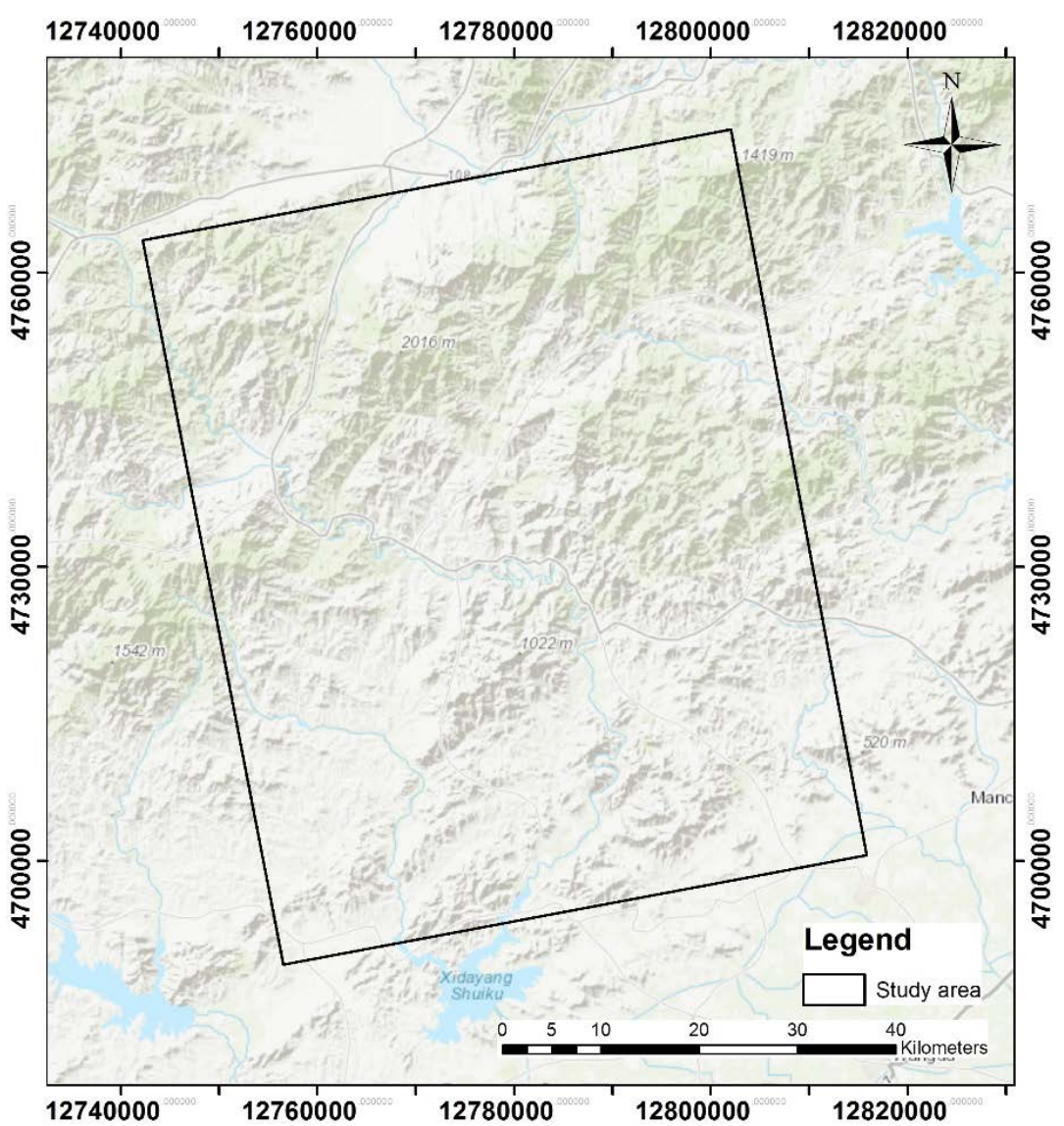

Figure 1. Studied area.

Table 1. List of Sentinel-1A images.

\begin{tabular}{cccccc}
\hline $\begin{array}{c}\text { Acquisition } \\
\text { date }\end{array}$ & $\begin{array}{c}\text { Time } \\
\text { interval (d) }\end{array}$ & $\begin{array}{c}\text { Normal } \\
\text { baseline (m) }\end{array}$ & $\begin{array}{c}\text { Acquisition } \\
\text { date }\end{array}$ & $\begin{array}{c}\text { Time } \\
\text { interval (d) }\end{array}$ & $\begin{array}{c}\text { Normal } \\
\text { baseline (m) }\end{array}$ \\
\hline 10-Oct-2015 & -384 & -7.175 & 21 -Nov-2016 & 24 & -105.135 \\
03-Nov-2015 & -360 & -75.906 & $03-$ Dec-2016 & 36 & -28.139 \\
27-Nov-2015 & -336 & 47.565 & $15-$ Dec-2016 & 48 & 47.473 \\
21-Dec-2015 & -312 & 10.070 & 27-Dec-2016 & 60 & 7.421 \\
14-Jan-2016 & -288 & -6.880 & 08-Jan-2017 & 72 & 17.620 \\
02-Mar-2016 & -240 & -98.897 & 01-Feb-2017 & 96 & -52.234 \\
26-Mar-2016 & -216 & -60.336 & 13-Feb-2017 & 108 & 4.017 \\
16-Oct-2016 & -12 & 51.428 & 25-Feb-2017 & 120 & 33.078 \\
28-Oct-2016 & 0 & 0 & 09-Mar-2017 & 132 & 30.734 \\
09-Nov-2016 & 12 & -51.358 & 02-Apr-2017 & 156 & -68.989 \\
\hline
\end{tabular}

the elevation of the target point through phase interference [32]. D-InSAR performs differential interference on two or multiple scene radar images and finally obtains the displacement of a certain point on the ground relative to the sensor. SBAS-InSAR uses the deformation information obtained by D-InSAR as the ob- 
servation to obtains high-precision time series deformation information by the least squares method [33]. In the SBAS-InSAR processing, a time baseline threshold and a space baseline threshold are given based on the specific data respectively. Based on the data in the study area, we used 220 days as time baseline threshold and $95 \mathrm{~m}$ as spatial baseline threshold. Then differential interference processing is performed on all the image pairs combined within the threshold. Finally, all differential interference results are uniformly settled by the least squares method [34]. The main unwrapping methods used in SBAS-InSAR processing include Minimum Cost Flow, Region Growing, Delaunay MCF [35]. In this paper we use Minimum Cost Flow. Considering all the pixels on the image, this algorithm uses the square grid to mask the pixels whose coherence is less than the threshold. This method can ensure that the data has a better unwrapping effect under long time baseline conditions. High-density time and space information in SBAS-InSAR can eliminate the atmospheric effect phase in addition to ensuring the coherence of data. Figure 2 is a flowchart of SBAS-InSAR processing.

\subsection{Experiment Design}

Coherence is the basis of interference, and spatial decorrelation is one of the most important factors affecting coherence. The spatial decorrelation formula is as follows.

$$
\gamma_{\text {spatial }}=\gamma_{\text {surface }} \cdot \gamma_{\text {volume }}
$$

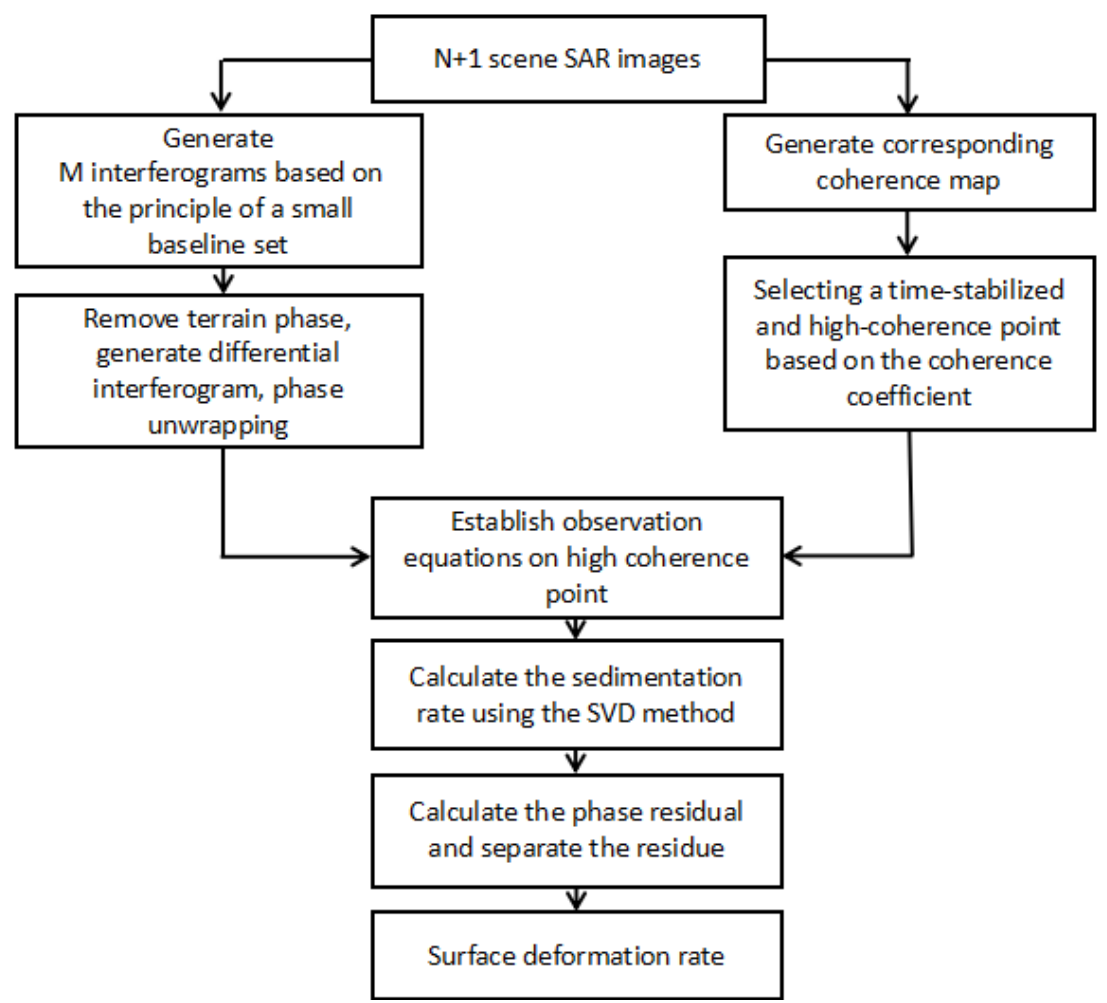

Figure 2. SBAS-InSAR processing flow chart. 
The total spatial decorrelation consists of volume scattering decorrelation and surface scattering decorrelation. In some areas where vegetation covers more, the volume scattering decorrelation is more dominant than the surface scattering decorrelation [36] [37]. Based on the dense vegetation in the test area, the influence of volume scattering correlation is more pronounced. By using the data of winter period, the influence of volume scattering decorrelation will be greatly reduced, but the long-time baseline may cause the surface scattering decorrelation. Next, the paper will verify the effect of long-time baseline on the results in areas where vegetation effects (body scattering decorrelation) are small.

Due to the lack of ground measured data in the line selection area, this paper selects Beijing, which is closer to the line selection area, as the verification area. We use data of the Beijing area from May 2015 to May 2016 with a one-year time baseline data to complete D-InSAR processing. The SRTM DEM with $30 \mathrm{~m}$ resolution was used to remove the terrain phase. After filtering, unwrapping, refinement and re-flattening the LOS surface deformation was obtained. As Figure 3 shows, the points whose value are smaller than zero were extracted to express LOS land subsidence in Beijing. There was an obvious subsidence funnel in the Chaoyang District, the eastern part of Beijing, which is consistent with the Beijing subsidence division given by the Beijing Institute of Hydrogeology and Engineering Geology [38]. The maximum LOS settlement from May 2015 to May 2016 was $127 \mathrm{~mm}$. The average LOS settlement in the central region of the subsidence funnel was $83 \mathrm{~mm}$. It was known that the true surface deformation in the Beijing area was dominated by vertical settlement, so the LOS settlement could be regarded as the projection in the LOS direction of the vertical settlement. Calculated with the radar incident angle of $36^{\circ}$, the average settlement of the subsidence center area was $104 \mathrm{~mm} /$ year. The settlement rate of the Chaoyang

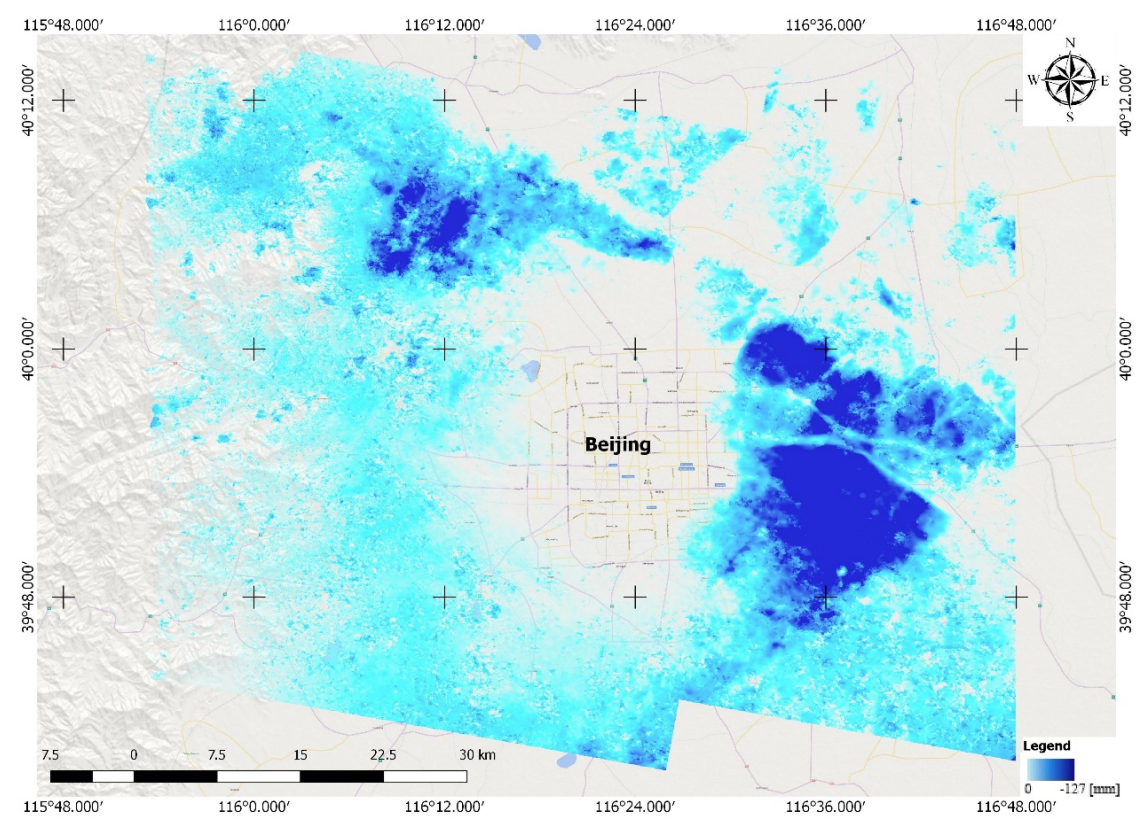

Figure 3. LOS settlement in Beijing area from May 2015 to May 2016. 
District measured by the Beijing Institute of Hydrogeology and Engineering Geology is the largest in Beijing, whose value was maintained at $115-140 \mathrm{~mm} / \mathrm{a}$ from 2014 to 2016 [38]. The results of D-InSAR processing on Sentinel-1A data were very close to those measured by ground stations. This experiment illustrates the possibility of obtaining higher precision results when the time baseline is one year and the condition of volume scattering is good. In the study area, the effect of body scattering decorrelation caused by trees in summer is serious. The average value of the coherence coefficient of many summer image pairs is less than 0.4 , and the coherence in the lush areas is less than 0.3 , which may cause large errors in the results. In order to obtain accurate surface deformation under long time series, we ignore the summer data and extend the time baseline threshold to 220 days. The next experiment is carried out.

\section{Processing and Discussion}

The images were processed by SARscape function on ENVI software. Firstly, we process D-InSAR with two Sentinel-1A images (October 10, 2015 with April 2, 2017). The SRTM DEM with $30 \mathrm{~m}$ resolution was used to remove the terrain phase. After these processing (filtering, using Minimal Cost Flow to unwrap, refinement and re-flattening), the LOS (line of sight) surface deformation was obtained.

Secondly, in order to get the deformation process during the 18 months, we further process SBS-InSAR from October 10, 2015 to April 2, 2017. The October 28,2016 was set as the super master image. The threshold for the time baseline is set to 220 days. The spatial baseline threshold is set to $2 \%$ of the critical baseline, approximately $95 \mathrm{~m}$. The 81 small baseline image pairs were generated, and the connection graph is showed in Figure 4. Then, the 81 pairs of images were dealt with interferometric processing, unwrapping with Minimal Cost Flow. The SRTM DEM with $30 \mathrm{~m}$ resolution was used to remove the terrain phase and generate the first interferogram. After the processing of refinement and re-flattening, two steps of inversions, and geocoding, the results of the LOS surface deformation process during October 10, 2015 to April 2, 2017 were obtained.

Figure 5 shows the LOS surface deformation of the study area from October 10, 2015 to April 2, 2017 obtained by D-InSAR. The positive values indicate that the surface moved toward the satellite, while the negative values show the movement in the opposite direction. As we can see from the figure, most of the pixels are green. It means that the surface deformation was very small and most of the deformation value was between $-20 \mathrm{~mm}$ and $20 \mathrm{~mm}$. This result indicates that the geological conditions are stable during the 18 months in the study area. Figure 6 shows the LOS surface deformation in the study area from October 10, 2015 to April 2, 2017 obtained by SBAS-InSAR. The standard deviation of the velocity is 6.43 which means a very small deformation in the studied area. And this result is similar to that using D-InSAR, it means that SBAS-InSAR and $\mathrm{D}$-InSAR have good consistency which can prove the accuracy of the results. We also see that the deformation is continuous in space which is good for power line 
Time-Position Plot

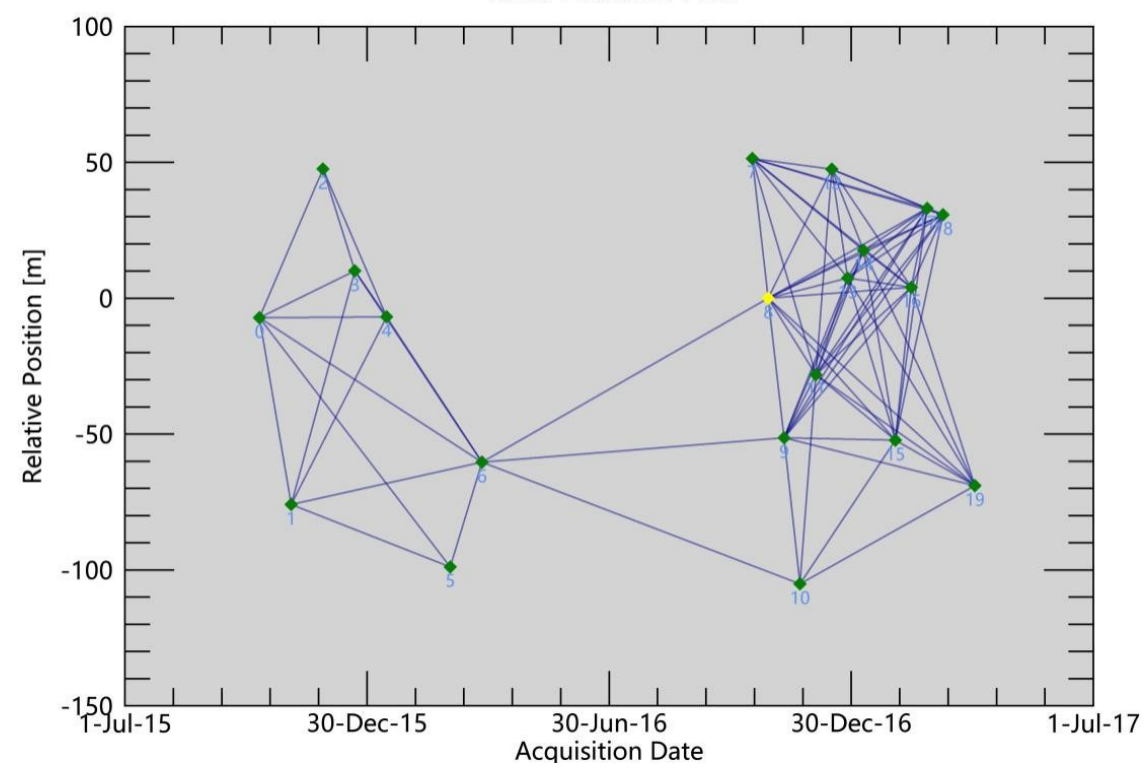

Figure 4. SBAS connection graph (The yellow point is the super master image).

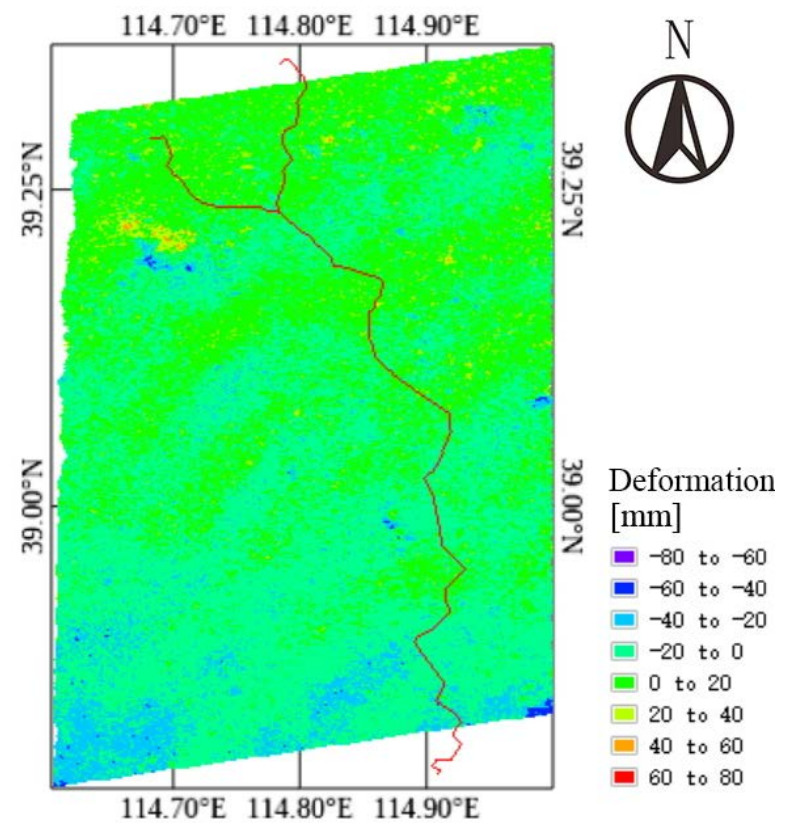

Figure 5. LOS deformation from October 10, 2015 to April 2, 2017(D-InSAR).

selection. These indicate that the proposed transmission line has a small surface deformation and a relatively stable geological condition in 18 months.

In order to illustrate the surface deformation process in the study area, ten high-coherence points on the transmission line were selected (mountain and plain) by considering the influence of terrain. The point locations are shown in Figure 7.

The cumulative deformation profiles of the ten points were drawn in Figure 8. According to the figure, there was no obvious difference between the points in 


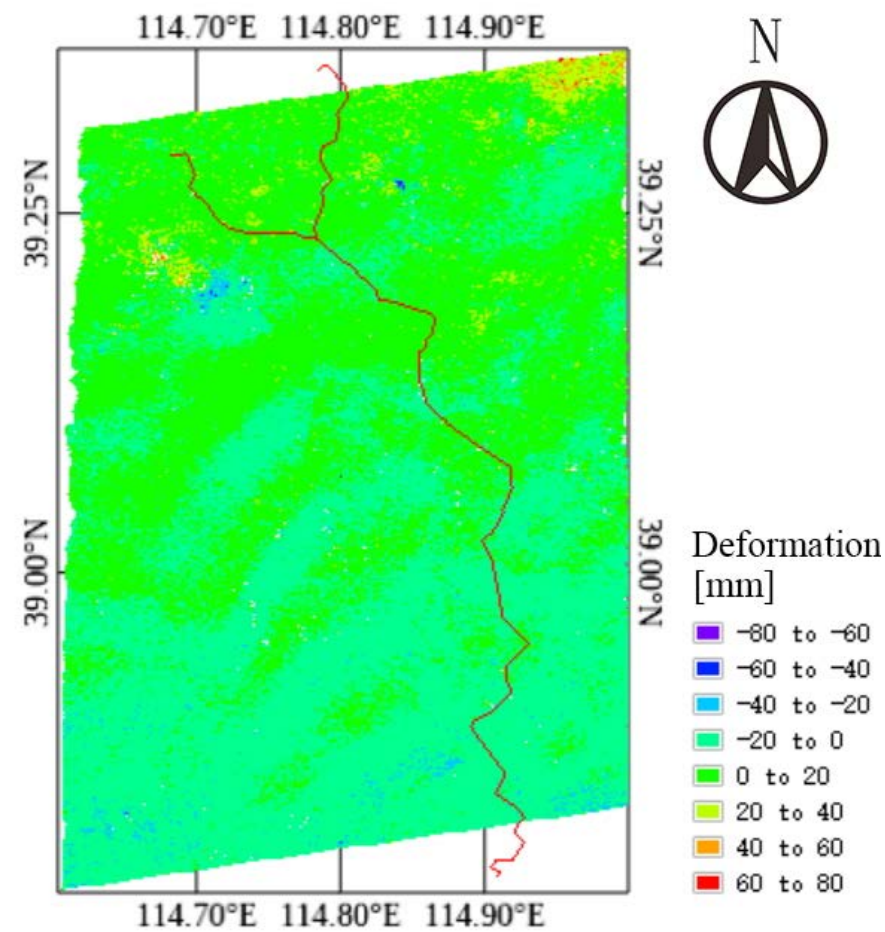

Figure 6. LOS deformation from October 10, 2015 to April 2, 2017(SBAS-InSAR).

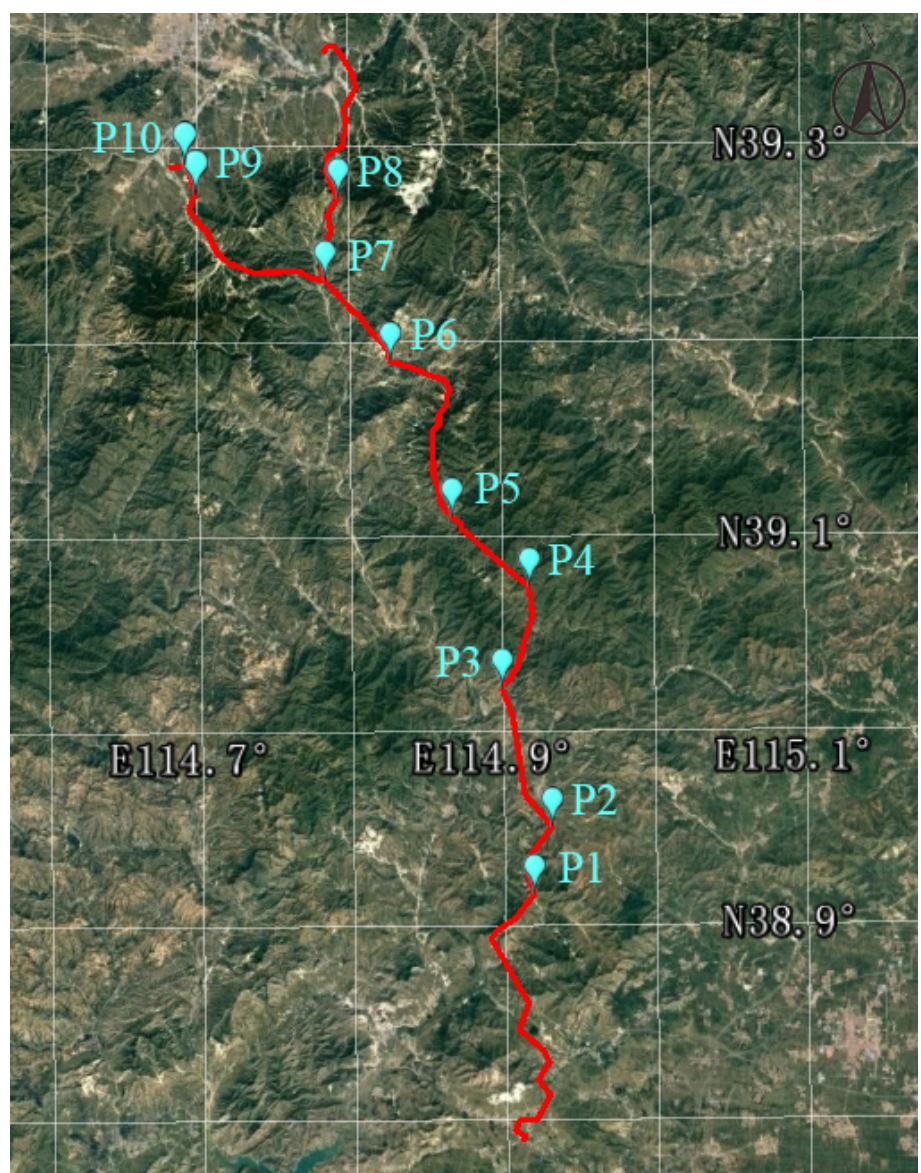

Figure 7. Ten high-coherence points selected. 


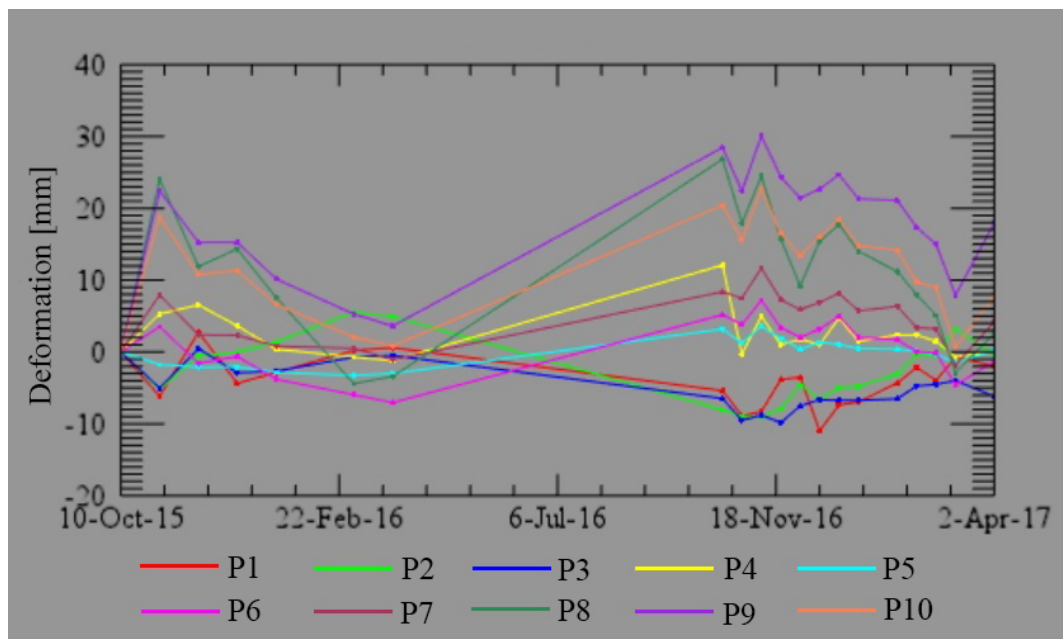

Figure 8. Cumulative deformation line chart.

the mountains and plains. The cumulative deformation lines were relatively flat. Because the data sample which has a high concentration of trees during summer period was removed, the deformation profiles were long straight lines in this period. Through the verification above, by doing this, the errors of the process will be reduced. While the three points in the north $(\mathrm{P} 8, \mathrm{P} 9, \mathrm{P} 10)$ had relatively large cumulative deformations in November, but the maximum cumulative deformation is less than $30 \mathrm{~mm}$, and the maximum cumulative deformation rate is only $12 \mathrm{~mm} / \mathrm{a}$. It can be seen that the deformation of the points on the power line is small, which indicates the stability of the power line.

\section{Conclusion}

This paper used Sentinel-1A data to carry out the historical surface deformation survey of the $220 \mathrm{kV}$ transmission line region to be built from Laiyuan to Quanyu, Hebei Province. It is proved that the surface of the area was in good condition for a long period of time. With the development of InSAR technology, the application field is also becoming wider and wider, but there are also some problems in the application process. For example, Sentinel-1A as a C-band data has poor penetration of vegetation, which may lead to serious volume scattering decorrelation. After analyzing and verifying the results of previous studies on volume scattering and surface scattering, we solved this problem. It also provides new ideas for the application of InSAR in some important areas. At present, the l-band data with strong vegetation penetration has the problem of insufficient data coverage and high price. Sentinel-1A is a free C-band data source, which is sensitive to micro-deformation detection. In some applications which need a long time series instead of special time points, such as power line selection, the proposed method in the paper will have great application prospects.

\section{Acknowledgements}

We are very grateful to ESA for being able to provide Sentinel-1A data and Bei- 
jing Institute of Hydrogeology and Engineering Geology for providing the settlement data measured by ground stations of Beijing Plain Area.

\section{Author Contributions}

All the authors contributed to this work, Y.M. conceived the idea. T.Y. Handled the Sentinel-1A data. Q.L. and T.Y. Completed the experiment and analysis. QL Summarized the experiment. Q.L. and T.Y. wrote this paper. T.Y. edited the paper. Wuttichai Boonpook modified the maps.

\section{Funding}

This work was financially supported by the Project for Follow-up Work in Three Gorges (2017HXNL-01) and the State Grid (CN No. GCB17201600036).

\section{Conflicts of Interest}

The authors declare no conflict of interest.

\section{References}

[1] Chen, G., Cheng, Z.F., Li, M.Q., Hu, Y. and Yuan, H. (2008) The Production of Remote Sensing Image Map and Its Application in Electric Power Survey Design. Electric Power Survey Design, No. 4, 22-24. (In Chinese)

[2] Chang, Z.L. and Yu, D.T. (2009) Application of Remote Sensing Image Technology in Electric Power Surveying and Line Selection-Electric Survey and Line Selection System Based on Lidarmapper's Stereo Image Mapping Technology. Geographic Information World, 7, 88-89. (In Chinese)

[3] Xiong, B.W., Wang, S., Zhao, B.B., Tan, Y.M. and Wu, C.S. (2017) Applicability of Domestic Satellite Remote Sensing Data in Power Line Selection. Mapping and Spatial Geographic Information, No. 12, 34-38. (In Chinese)

[4] Cao, M.Y. (2014) Discussion on the Settlement Treatment of Power Equipment Foundation. Science and Technology Wind, No. 21, 31. (In Chinese)

[5] Zhu, X., Kang, X. and Li, X.Y. (2017) Application of InSAR Technology in surface Deformation Monitoring of Electric Power Facilities. Electric Power Survey Design, No. s1. (In Chinese).

[6] Colesanti, C. and Wasowski, J. (2006) Investigating Landslides with Space-Borne Synthetic Aperture Radar (SAR) Interferometry. Engineering Geology, 88, 173-199. https://doi.org/10.1016/j.enggeo.2006.09.013

[7] Bathrellos, G.D., Gaki-Papanastassiou, K., Skilodimou, H.D., Papanastassiou, D. and Chousianitis, K.G. (2012) Potential Suitability for Urban Planning and Industry Development Using Natural Hazard Maps and Geological-Geomorphological Parameters. Environmental Earth Sciences, 66, 537-548. https://doi.org/10.1007/s12665-011-1263-x

[8] Chen, W., Zhai, G., Ren, C., Shi, Y. and Zhang, J. (2018) Urban Resources Selection and Allocation for Emergency Shelters: In a Multi-Hazard Environment. International Journal of Environmental Research \& Public Health, 15, 1261. https://doi.org/10.3390/ijerph15061261

[9] Yerro, A., Corominas, J., Monells, D. and Mallorquí, J.J. (2014) Analysis of the Evolution of Ground Movements in a Low Densely Urban Area by Means of DIn- 
SAR Technique. Engineering Geology, 170, 52-65.

https://doi.org/10.1016/j.enggeo.2013.12.002

[10] Fernandez, P., Irigaray, C., Jimenez, J., Hamdouni, R., Crosetto, M., Monserrat, O. and Chacon, J. (2009) First Delimitation of Areas Affected by Ground Deformations in the Guadalfeo River Valley and Granada Metropolitan Area (Spain) Using the DInSAR Technique. Engineering Geology, 105, 84-101. https://doi.org/10.1016/j.enggeo.2008.12.005

[11] Yang, K., Li, Y., Huang, G.M., Chen, C. and Wu, Z.P. (2016) Monitoring Building Deformation with InSAR: Experiments and Validation. Sensors, 16, 2182. https://doi.org/10.3390/s16122182

[12] Batuhan, O., Filiz, S., Shimon, W. and Enrique, C. (2016) Time Series Analysis of InSAR Data: Methods and Trends. Isprs Journal of Photogrammetry \& Remote Sensing, 115, 90-102. https://doi.org/10.1016/j.isprsjprs.2015.10.003

[13] Perissin, D. and Wang, T. (2011) Time-Series InSAR Applications over Urban Areas in China. IEEE Journal of Selected Topics in Applied Earth Observations \& Remote Sensing, 4, 92-100. https://doi.org/10.1109/JSTARS.2010.2046883

[14] Qin, X.Q., Yang, T.L., Yang, M.S., Zhang, L. and Liao, M.S. (2017) Health Diagnosis of Major Transportation Infrastructures in Shanghai Metropolis Using High-Resolution Persistent Scatterer Interferometry. Sensors, 17, 2770. https://doi.org/10.3390/s17122770

[15] Zhao, Q., Lin, H., Jiang, L.M., Chen, F.L. and Cheng, S.L. (2009) A Study of Ground Deformation in the Guangzhou Urban Area with Persistent Scatterer Interferometry. Sensors, 9, 503-518. https://doi.org/10.3390/s90100503

[16] Colesanti, C., Ferretti, A., Novali, F. and Prati, C. (2003) SAR Monitoring of Progressive and Seasonal Ground Deformation Using the Permanent Scatterers Technique. IEEE Transactions on Geoscience \& Remote Sensing, 41, 1685-1701. https://doi.org/10.1109/TGRS.2003.813278

[17] Liao, M.S., Tang, W., Wang, T., Balz, T. and Zhang, L. (2012) Application of High Resolution SAR Data in Landslide Monitoring in the Three Gorges Reservoir Area. Chinese Science: Earth Science, 42, 217. (In Chinese)

[18] Liao, M.S., Pei, Y.Y., Wang, H.M., et al. (2012) Permanent Scatterer Radar Interferometry for Monitoring Shanghai Ground Subsidence. Shanghai Land Resources, 33, 5-10. (In Chinese)

[19] Dong, J., Liao, M.S., Xu, Q., Zhang, L., Tang, M.G. and Gong, J.Y. (2018) Detection and Displacement Characterization of Landslides Using Multi-Temporal Satellite SAR Interferometry: A Case Study of Danba County in the Dadu River Basin. Engineering Geology, 240, 95-109. https://doi.org/10.1016/j.enggeo.2018.04.015

[20] Herrera, G., Notti, D., García-Davalillo, J., Mora, O., Cooksley, G. and Sánchez, M. (2011) Analysis with C- and X-Band Satellite SAR Data of the Portalet Landslide Area. Landslides, 8, 195-206. https://doi.org/10.1007/s10346-010-0239-3

[21] Yang, Z.F., Li, Z.W., Zhu, J.J., Yi, H.W., Hu, J. and Feng, G.C. (2017) Deriving Dynamic Subsidence of Coal Mining Areas Using InSAR and Logistic Model. Remote Sensing, 9, 125. https://doi.org/10.3390/rs9020125

[22] Fan, H.D., Wei, G., Qin, Y., Xue, J.Q. and Chen, B.Q. (2014) A Model for Extracting Large Deformation Mining Subsidence Using D-InSAR Technique and Probability Integral Method. Transactions of Nonferrous Metals Society of China, 24, 1242-1247. https://doi.org/10.1016/S1003-6326(14)63185-X

[23] Perski, Z., Hanssen, R., Wojcik, A. and Wojciechowski, T. (2009) InSAR Analyses of 
Terrain Deformation near the Wieliczka Salt Mine, Poland. Engineering Geology, 106, 58-67. https://doi.org/10.1016/j.enggeo.2009.02.014

[24] Moro, M., Saroli, M., Stramondo, S., Bignami, C., Albano, M. and Falcucci, E. (2017) New Insights into Earthquake Precursors from InSAR. Sci Rep., 7, 12035. https://doi.org/10.1038/s41598-017-12058-3

[25] Jo, M.J., Jung, H.S. and Yun, S.H. (2017) Retrieving Precise Three-Dimensional Deformation on the 2014 m6.0 South Napa Earthquake by Joint Inversion of Multi-Sensor SAR. Scientific Reports, 7, 5485.

https://doi.org/10.1038/s41598-017-06018-0

[26] Wright, T.J., Parsons, B.E., Jackson, J.A., Haynes, M., Fielding, E.J. and England, P.C. (1999) Source Parameters of the 1 October 1995 Dinar (Turkey) Earthquake from SAR Interferometry and Seismic Bodywave Modelling. Earth \& Planetary Science Letters, 172, 23-37. https://doi.org/10.1016/S0012-821X(99)00186-7

[27] Bignami, C., Burrato, P., Cannelli, V., Chini, M., Falcucci, E. and Ferretti, A. (2012) Coseismic Deformation Pattern of the Emilia 2012 Seismic Sequence Imaged by Radarsat-1 Interferometry. Annals of Geophysics = Annali di Geofisica, 55, 789-795.

[28] Salvi, S., Stramondo, S., Funning, G.J., Ferretti, A., Sarti, F. and Mouratidis, A. (2012) The Sentinel-1 Mission for the Improvement of the Scientific Understanding and the Operational Monitoring of the Seismic Cycle. Remote Sensing of Environment, 120, 164-174. https://doi.org/10.1016/j.rse.2011.09.029

[29] Bekaert, D.P.S., Hamlington, B.D., Buzzanga, B. and Jones, C.E. (2017) Spaceborne Synthetic Aperture Radar Survey of Subsidence in Hampton Roads, Virginia (USA). Sci Rep., 7, 14752. https://doi.org/10.1038/s41598-017-15309-5

[30] Wang, H.Y., Chang, L. and Markine, V. (2018) Structural Health Monitoring of Railway Transition Zones Using Satellite Radar Data. Sensors, 18, 413. https://doi.org/10.3390/s18020413

[31] Dai, K., Liu, G.X., Li, Z.H., Ma, D.Y., Wang, X.W., Zhang, B., Tang, J. and Li, G.Y. (2018) Monitoring Highway Stability in Permafrost Regions with X-Band Temporary Scatterers Stacking InSAR. Sensors, 18, 1876. https://doi.org/10.3390/s18061876

[32] Han, J., Zhao, Y.J., Tao, L. and Huang, J. (2015) PS Monitoring Surface Settlement Algorithm and Its Application. Journal of Information Engineering University, 16, 458-462. (In Chinese).

[33] Berardino, P., Fornaro, G., Lanari, R. and Sansosti, E. (2003) A New Algorithm for Surface Deformation Monitoring Based on Small Baseline Differential SAR Interferograms. IEEE Transactions on Geoscience \& Remote Sensing, 40, 2375-2383. https://doi.org/10.1109/TGRS.2002.803792

[34] Liu, P., Li, Z.H., Hoey, T., Kincal, C., Zhang, J.F., Zeng, Q.M. and Muller, J.P. (2013) Using Advanced InSAR Time Series Techniques to Monitor Landslide; Movements in Badong of the Three Gorges Region, China. International Journal of Applied Earth Observations \& Geoinformation, 21, 253-264. https://doi.org/10.1016/j.jag.2011.10.010

[35] Costantini, M. and Rosen, P.A. (1999) A Generalized Phase Unwrapping Approach for Sparse Data. IEEE 1999 International Geoscience and Remote Sensing Symposium, 1, 267-269. https://doi.org/10.1109/IGARSS.1999.773467

[36] Garestier, F., Duboisfernandez, P.C. and Champion, I. (2008) Forest Height Inversion Using High-Resolution P-Band Pol-InSAR Data. IEEE Transactions on Geoscience \& Remote Sensing, 46, 3544-3559.

https://doi.org/10.1109/TGRS.2008.922032 
[37] Langley, H., et al. (2007) Use of C-Band Ground Penetrating Radar to Determine Backscatter Sources within Glaciers. IEEE Transactions on Geoscience \& Remote Sensing, 45, 1236-1246. https://doi.org/10.1109/TGRS.2007.892600

[38] Cheng, L.P., Wang, X.H., Zhang, Q.W., Zhang, T., Wu, Z.K. (2018) Influence of Transferring Yangtze River Water into Beijing on Ground Subsidence and Trend Analysis. Yellow River, 40, 93-97. (In Chinese) 